\title{
The Influence of Smoking Habit to Voice Handicap Index Score
}

\section{Original Article}

\author{
Asti Widuri', Eka Yoga Wiratama ${ }^{2}$ \\ ${ }^{1}$ Department of Otorhinolaryngology, Faculty of Medicine and Health Sciences, Universitas \\ Muhammadiyah Yogyakarta, ${ }^{2}$ PKU Muhammadiyah Hospital, Yogyakarta, Indonesia.
}

\begin{abstract}
Introduction: The health voice production depends on vocal folds vibration and resonance. Anatomical changes of the vocal folds soft tissue (epithelium, ligament, muscle) can cause functional problems results in voice disorders. The vocal folds react to smoking, from irritate the mucous to the tissue changes or dysplasia that degradation of voice performance in daily living.

Aim: This study determined the influence of smoking habits to the voice handicap score by Voice Handicap Index score (VHI).

Patients and Methods: The design was a retrospective cohort study from 96 adults that identified level of voice fatigue through VHI. They were divided into 3 groups: a group of active smokers, passive smokers and nonsmokers. Chi-square test and regression nominal test was used in this study.

Results: Voice fatigue (VHI score $>20)$ in both active smokers (13.54\%) and passive smokers $(15.62 \%)$ compared with nonsmokers $(6.25 \%)$, by Chi-square test results was $p=0.047(p<0.05)$. Nominal regression test between 3 groups of samples were $(\mathrm{RR}=3.0, \mathrm{CI} 95 \%=0.95$ to 9.21$)$ between the group of active smokers and passive smokers $(\mathrm{RR}=3.8, \mathrm{CI}$ $95 \%=1.23-11.80)$.

Conclusion: Smoking habits influence the voice handicap score in both active smokers and passive smokers compared with nonsmokers. Active smokers have a risk of voice fatigue 3 times than nonsmokers and passive smokers have a risk 3.8 times than non-smokers.
\end{abstract}

Key Words: Smoking, VHI score, voice.

Received: 12 August 2020, Accepted: 16 December 2020

Corresponding Author: Asti Widuri, ENT Specialist, Department of Otorhinolaryngology, Faculty of Medicine and Health Sciences, Universitas Muhammadiyah Yogyakarta, Indonesia, Tel.: +6274 4539091, E-mail: astiwiduri@gmail.com

ISSN: 2090-0740, 2021 Vol.22

\section{INTRODUCTION}

The tobacco consumption in developing countries has increased. Most of them started to consume tobacco since teenager although government has some intervention programs to prevent and reduce of smoking in adolescents. These programs are the anti-smoking curriculum, behavior change intervention, and peer education. ${ }^{[1,2]}$ Smoking is common harmful habits in the world, caused around 5.7 million people died due to various diseases related to smoking, $6.9 \%$ of years of life lost, and $5.5 \%$ of disability. ${ }^{[3,4]}$ Smokers have a higher risk of respiratory disease, sinusitis, gastroesophageal disease, cardiac diseases and cancer. ${ }^{[5]}$

Chronic smoking is known as major risk factor for laryngeal pathology such as benign laryngeal neoplasm and cancer. Cigarette smoke contains many chemical substances, some of them are typical carcinogens identified by bioassays that significantly related to the onset of laryngeal pathology but the evident effects for voice health still insufficient. ${ }^{[6,7]}$ Voice disorders or dysphonia caused by anatomic changes vocal folds soft tissue, influenced by many factors such as upper respiratory infection, rhinosinusitis, oesofageal reflux, environmental factors like talking loudly or for long time, talking over background noise, and smoking. ${ }^{[8,9]}$

Tobacco smoking influence the larynx histology because of its irritant effects that reduce the cilliar movement, mucus concentration on the vocal fold superficial mucosal layer, changes vibratory pattern and lowering fundamental frequency resulting in a deterioration of vocal quality and pitch. Inflammation, erythema and irritation of vocal folds epithelial changes the voice perceptual, acoustic, and aerodynamic voice characteristics. ${ }^{[10]}$

Although smoking had a significant relationship with laryngeal diseases, relationship between smoking and laryngeal disorders in epidemiological studies is controversial. Epidemiological study on Korean adults showed a significant relationship smoking with laryngeal 
disorders, although there was no significant relationship between smoking and dysphonia in the previous study on the general US population. ${ }^{[11,12]}$ The difference result of the relationship between smoking and laryngeal disorders possible depend on the survey method used, based on the questionnaire survey or biochemical tests, and difference population and gender sample. ${ }^{[13]}$

The early laryngeal disease symptom before dysphonia was vocal fatigue that can be measured by VHI. VHI is a useful tool in measuring functional outcome for voice disorders on non-symptomatic smokers, it assess not only the bio-psychosocial impact of voice disorders but also screening tool to distinguish between subjects with voice dysfunction or normal. ${ }^{[14]}$ This study aimed to investigate the effect of smoking on voice handicap score and to determine differences in the incidence of fatigue voice by voice handicap score in active smokers, passive smokers and nonsmokers.

\section{PATIENTS AND METHODS:}

The study design was a cross sectional study. The participants of this study were 96 male students of the Faculty of Medicine and Health Sciences UMY aged 18-22 years. They were divided into 3 groups based on their smoking habits: 32 were active smokers, 32 were passive smokers and 32 were non-smoker. Sound level of voice fatigue was identified by using Voice Handicap
Index score (VHI) which widely accepted questionnaire for research purpose and clinical used. It has been adapted in many languages, in this research the VHI questionnaire was translated and validated in Indonesian by Kadriyan 2008. ${ }^{[15]}$

The VHI assess three aspects (biopsychosocial) impact on voice, the questionnaires consisted of 30 questions under three domain on respective subscales measured the physical (VHI-P), emotional (VHI-E) and functional (VHI-F) aspects of voice. Respondents filled the VHI by themselves which used Likert scale: never (0), almost never (1), sometimes (2), almost always (3), and always (4). The total score of VHI varies $0-120$, For each subdomains the sub score varies between 0 to 40 . The low VHI value, $0-20$ points, means the absence of voice problems, a score of 20-40 points indicating slight voice problems, a score of 41-60 points indicating a moderate handicap level, while that of 61-120 points indicates severe voice disorders. Chisquare test was used in the statistical.

\section{RESULTS:}

The study group consisted of 96 respondents, each group were 32 participants (active smokers, passive smokers and non-smoker). The results showed that there were no significant differences in allergic rhinitis, voice abuse or coffee consumption. Characteristics of respondents based on smoking activity are demonstrated in (Table 1).

Table 1: Sample characteristics $(n=96)$

\begin{tabular}{llllll}
\hline Risk Factor & Active smokers & $\begin{array}{l}\text { (n Passive smokers } \\
\text { \%) }\end{array}$ & $\begin{array}{l}\text { Non-smokers } \\
\text { (n \%) }\end{array}$ & $P$ \\
\hline Allergic rhinitis & Yes & $05(05.21)$ & $08(08.33)$ & $06(06.25)$ & 0.432 \\
& No & $27(28.13)$ & $24(25.00)$ & $26(27.08)$ & \\
Voice Abuse & Yes & $12(12.50)$ & $11(11.46)$ & $12(12.50)$ & 0,767 \\
& No & $20(20.83)$ & $21(21.86)$ & $20(20.83)$ & \\
Coffee consumption & Yes & $11(11.46)$ & $09(09.38)$ & $02(02.08)$ & 0,199 \\
& No & $21(21.86)$ & $23(23.96)$ & $30(31.25)$ & \\
\hline
\end{tabular}

In the characteristics risk factor of rhinitis patients was $19(19.79 \%)$, voice abuse $35(36.46 \%)$ and consumption of caffeine $22(22.92 \%)$. The normal VHI score was highest in non-smoker group $(27.08 \%)$ and vocal fatigue incidency $(3.16 \%)$ in both active and passive smoker (Tabel 2).

Table 2: Smokers habits according to VHI scores

\begin{tabular}{ccccc}
\hline $\begin{array}{c}\text { VHI } \\
\text { Scores }\end{array}$ & $\begin{array}{c}\text { Active smokers } \\
(\mathrm{n} \%)\end{array}$ & $\begin{array}{c}\text { Passive smokers } \\
(\mathrm{n} \%)\end{array}$ & $\begin{array}{c}\text { Non-smokers } \\
(\mathrm{n} \%)\end{array}$ & $P$ \\
\hline$<20$ & $19(19.79)$ & $17(17.71)$ & $26(27.08)$ & \\
$20-40$ & $10(10.42)$ & $12(12.50)$ & $06(06.25)$ & 0.128 \\
$41-60$ & $03(03.16)$ & $03(03.16)$ & $0(00.00)$ & $0(00.00)$ \\
$>60$ & $0(00.00)$ & $0(00.00)$ & $32(33.33)$ & \\
$\mathrm{n}$ & $32(33.33)$ & $32(33.33)$ & \\
\hline
\end{tabular}


The relationship between smoking habits and VHI score

The relationship between smoking habits and vocal fatigue is presented in table 3 , it was observed that smokers' habits had a correlation with VHI scores, the analysis Chi-Square value is 6.102 with a significance level
( $P$ value $) 0.047$. The results pointed out that there is an influence of smoking on voice fatigue. VHI can be used as a validated tool for smokers without significant complaint for measuring functional outcomes for voice disorders.

Table 3: Relationship between smoking habits and vocal fatigue

\begin{tabular}{lccc}
\hline Smoking habits & $\begin{array}{c}\text { Vocal fatigue } \\
\text { N (\%) }\end{array}$ & $\begin{array}{c}\text { No Vocal Fatigue } \\
\text { N (\%) }\end{array}$ & P value \\
\hline Active smokers & $13(13.54)$ & $19(19.79)$ & 0.047 \\
Passive smokers & $15(15.62)$ & $17(17.70)$ & \\
Non- smokers & $06(06.25)$ & $26(27.08)$ & \\
\hline
\end{tabular}

\section{DISCUSSION}

According to $\mathrm{Xi}$ B's research (2016) the characteristics subjects in this study similar to the statement that $90 \%$ of smokers start to consume tobacco at teenager before 18 years based on the data from 68 developing countries since 2006 to 2013 . Adolescence is population with a high-risk development phase to start smoking and half of the smokers who smoke during adolescence tends to continue smoking for the next 15-20 years, so smoking prevention among teens is essential. ${ }^{[16,17]}$

Studies showed the relationship between smoking and voice health, the mechanism were as risk factor for voice disorder, change voice characteristics, and influence the subjective perception of voice problems such higher voice use fatigue and more frequent voice interruption. ${ }^{[18]}$ This study showed that smokers habits had a correlation with VHI scores, the analysis Chi-Square value was a significance level ( $P$ value $=0.047)$ (tabel 3$)$. This result in line with Tafiadis (2017) who reported the correlation between VHI and acoustic parameters (voice fundamental frequency, fundamental frequency parameters and amplitude parameters) of young female smokers in Greece. ${ }^{[19]}$ Byeon (2015) also reported that excessive cigarette smoking/ chronic smoking had an independent relationship with dysphonia, current smokers had a 1.8 times $(\mathrm{OR}=1.77,95 \% \mathrm{CI}(1.17-2.68))$ higher risk for self-reported voice problems than non-smokers. ${ }^{[20]}$

Although various studies summary the negative affect of smoking habits there still not enough evidence to establish the relation between smoking and voice, because epidemiological studies revealed that smoking is not the only factor which cause voice disorders. This study have limitations of representative sample because voice characteristic can be also influenced by several factors namely infection, allergies/asthma, voice habits and also dietary habits. However, it can be confirmed that smoking had significant and moderate effects on some parameter voice such as fundamental frequency, maximum phonation time, voice handicap index and physical functions. Therefore, it is needed to identify the effects of smoking on the voice of smokers with RCT experiments or cohort studies to confirm the effect sizes of variable to the basic preventing voice disorders. ${ }^{[12]}$

The larynx pathology requires multidimensional approach assessment such as physical examination with laryngovideostroboscopy, objective voice measurement, perceptual examination of voice and self-assessment of voice related patient quality of life. VHI is a reliable tool to assess the bio-psychosocial impact of voice disorders in laryngological cases and the effect on quality of life but also applicable as screening tools to distinguish subjects with and without voice dysfunction ${ }^{[14]}$. The mean VHI score (overall and subscale scores) in the study group with benign larynx disorder such as vocal fold masses, vocal fold paresis/paralysis and functional dysphonia and the control group among normal individual larynx function differed significantly. ${ }^{[21]}$

The study which used samples from hospital and specific institution like used in this study have different result from study which has been done in community populations, which has no significant relationship between smoking and dysphonia. The results from previous studies reported insignificant effect of smoking variables on voiceless fatigue. This is likely due to previous research taking general or less specific samples. ${ }^{[11,12]}$ 
Smoking related to organic voice disorders rather than functional voice disorders, but excessive smoking is irritating and drying the vocal cords mucosa. It can result in inflammation and changed epithelial lead to changes in voice. In the present study, the purposed was to determine whether tobacco smoked had any effect on voice at many stages of the smoking habit and to quantify this effect by means of objective measures provided by VHI parameters. All the respondents were young productive adults of both sexes between 18 and 22 years of age and most of them had a smoking history shorter than one decade. Another factor that influence the patient perception of voice impairment likes occupation that greater voice need demand demonstrated high sensitivity on voice changes.

\section{CONCLUSION}

The result showed that smoking habits, both active and passive has effect on vocal fatigue by higher voice handicaps index score. Although there is evidence on smoking effect, further studies are therefore necessary to determine smoking habits classification, age at which participants started smoking, number of cigarettes smoked per day/ heavy or light smokers.

\section{RECOMMENDATIONS AND LIMITATIONS}

Assessment of laryngeal pathology should be better with laryngeal investigation videostroboscopy. In terms of limitations, this study only focused on male smokers because limitation of female smokers in our population, the data surveyed with subjective self-reported questionnaires not confirmation by biochemical tests for smoking habit and physical examination.

\section{CONFLICT OF INTEREST}

There are no conflicts of interest.

\section{REFERENCES}

1. $\mathrm{Ng} \mathrm{M}$, Freeman $\mathrm{MK}$, Fleming $\mathrm{TD}$, Robinson $\mathrm{M}$, Dwyer-Lindgren L, Thomson B, et al. Smoking prevalence and cigarette consumption in 187 countries, 1980-2012. JAMA. 2014;311(2):183-92. doi:10.1001/jama.2013.284692.

2. Huriah T, Lestari VD. School-based Smoking Prevention in Adolescents in Developing Countries: A Literature Review. Open Access Maced J Med Sci. 2020 Feb 05; 8(F):1-6. https://doi.org/10.3889/oamjms.2020.4336

3. World Health Organization. WHO Report on the Global Tobacco Epidemic. 2014. WHO, Geneva, Switzerland.
4. Lim SS, Vos T, Flaxman AD, et al. A comparative risk assessment of burden of disease and injury attributable to 67 risk factors and risk factor clusters in 21 regions, 1990-2010: a systematic analysis for the Global Burden of Disease Study 2010. Lancet. 2012; 380(9859):2224-2260.

5. Guimaraes \& Abberton. Health and Voice Quality in Smokers: An Exploratory Investigation. Logoped Phoniatr Vocol. 2005;30(3-4):185-91. doi: 10.1080/14015430500294114

6. Rodgman, A., Perfetti, TA. The chemical components of tobacco and tobacco smoke. 2009. Boca Raton: CRC Press, Taylor \& Francis Group.

7. Schultz, P. Vocal fold cancer. European Annals of Otorhinolaryngology, Head and Neck Diseases. 2011. 128, 301-308.

8. Vilkman E Occupational safety and health aspects of voice and speech professions. Folia Phoniatr Logop, 2004;56: 220-253.

9. Awan SN, Morrow DL. Videostroboscopic characteristics of young adult female smokers vs. nonsmokers. J Voice. 2007; 21: 211-223.

10. Gnjatić M, Stanković P, Đukić V. The effect of smoking and forced use of the voice to development of the vocal polyps. Acta Chir Yug. 2009; 56: 27-32.

11. Byeon H. The risk factors of laryngeal pathology in Korean adults using a decision tree model. J Voice. 2015; 29: 59-64.

12. Roy N, Merrill RM, Gray SD et al. Voice disorders in the general population: prevalence, risk factors, and occupational impact. Laryngoscope. 2005; 115:198895.

13. Byeon H, Lee D, Cho S. Relationship between women's smoking and laryngeal disorders based on the urine cotinine test: results of a national population based survey. BMJ Open. 2016; 6: e012169. doi: 10.1136/bmjopen-2016-012169

14. Niebudek-Bogusz E, Kuzańska A, Woznicka E et al. Assessment of the voice handicap index as a screening tool in dysphonic patients. Folia Phoniatr Logop.2011; 63: 269-272.

15. Kadriyan H, Soekardono S, Rianto B. Pengaruh bising terhadap gangguan vokal pada guru sekolah dasar. ORLI. 2008; 38(2): 24-32. 
16. Xi B, Liang Y, Liu Y, Yan Y. Tobacco use and secondhand smoke exposure in young adolescents aged 12 15 years: data from 68 low-income and middle-income countries. 2016.

17. Ho SY, Chen J, Liung LT, Mok HY, Wang LJ. Adolescent Smoking in Hong Kong: Prevalence, Psychosocial Correlates, and Prevention. Journal of Adolescent Health. 2019 ;64:19-27.

18. Pinar D, Cincik H, Erkul E, Atila G. Investigating the Effects of Smoking on Young Adult Male Voice by Using Multidimensional Methods. Journal of Voice,2016; 30(2), 721-725. https://doi.org/10.1016/j. jvoice.2015.07.007
19. Tafiadis D, Toki EI, Miller KJ, Ziavra N. Effects of Early Smoking Habits on Young Adult Female Voices in Greece. J Voice. 2017; 31: 728-732. https://doi.org/10.1016/j.jvoice.2017.03.012

20. Byeon H, Cha S. Evaluating the effects of smoking on the voice and subjective voice problems using a metaanalysis approach. Scientific Reports. 2020; 10: 4720 https://doi.org/10.1038/s41598-020-61565-3

21. Woisard V, Bodin S, Yardeni E, Puech M. The Voice Handicap Index: correlation between subjective patient response and quantitative assessment of voice. J Voice 2007; 21: 623-631. 